\title{
REVIEW \\ Self-harm and suicide before and after spinal cord injury: a systematic review
}

\author{
P Kennedy ${ }^{1,2}$ and L Garmon-Jones ${ }^{1}$
}

Study design: This is a systematic literature review.

Objectives: The objectives of this study were to investigate, first, the proportion of spinal cord injury (SCI) caused by suicidal behaviour; second, the proportion of deaths in the $\mathrm{SCl}$ population caused by suicide; and third, the risk factors associated with suicidal behaviour.

Setting: This study was conducted in the UK.

Methods: AMED, EMBASE, HMIC, BNI, Medline, PsycInfo, CINAHL and HEALTH BUSINESS ELITE were searched between January and February 2016, identifying a total of 404 articles published between 1990 and 2016. Full articles, written in English, looking at suicide before and after $\mathrm{SCl}$ were selected. On the basis of the inclusion criteria, 22 relevant articles were included in this literature review.

Results: Studies reported that between 0 and $6.8 \%$ of individuals with $\mathrm{SCl}$ had acquired their injury as a result of attempted suicide. The predominant method used in these attempts was deliberate falling/jumping from buildings and bridges. Suicidal behaviour post $\mathrm{SCl}$ was frequently reported as a cause of death; studies reported that between 5.8 and $11 \%$ of deaths were a result of suicide. The predominant methods used were gunshot and overdose. Psychiatric diagnoses were identified to be a major risk factor for suicidal behaviour.

Conclusion: Individuals with $\mathrm{SCl}$ are at risk of attempting suicide; this risk is increased by the presence of a psychiatric diagnosis. There is a crucial need for risk assessment and psychological intervention for individuals with mental health issues following SCl. Spinal Cord (2017) 55, 2-7; doi:10.1038/sc.2016.135; published online 27 September 2016

\section{INTRODUCTION}

Suicidal behaviour refers to the incidence of attempted suicide with some intent to end one's own life. ${ }^{1}$ The cost of suicidal behaviour is high, not only to the individual but also to the mental, physical and emotional state of their family and friends, as well as impacting on public resources. $^{2}$

Individuals with spinal cord injury (SCI) have been reported to be at an increased risk of suicide compared with the general population; ${ }^{3}$ however, different studies have suggested differing levels of risk. It is therefore important to explore this risk further and explore the factors that can increase this risk. Assessing the risk of suicide associated with SCI is a complex issue; many SCIs are caused by dangerous risk-taking behaviour, or strenuous physical activity. It is suggested that these individuals, in particular, are at increased risk of impulsive, dangerous, self-harming or suicidal behaviours irrespective of the consequence of their injury. ${ }^{4}$ However, this theory of pre-existing increased risk cannot apply to all individuals with SCI, and examining other risk factors is necessary. There is also an increased risk of suicidal behaviour post SCI as a consequence of the sudden impact of the injury and its associated impact on emotions and psychological well-being.

This literature review aims to investigate, first, the proportion of SCI caused by suicidal behaviour; second, the proportion of deaths in the SCI population caused by suicide; and third, the risk factors associated with suicidal behaviour. Exploring suicidal behaviour before SCI enables the identification of risk factors for SCI, and can inform future research and clinical practice. In addition, previous research has suggested that earlier attempted suicides increase the risk of later successful attempts. ${ }^{5}$ Suicide has been described by Berman et al. ${ }^{4}$ as a 'complex entity, involving biological, genetic and environmental risk factors.'(p.4)'. Our literature review aims to explore these factors in detail, specifying the factors associated with increased suicidal risk. In reviewing the current literature, trends can be identified that may provide guidance to required intervention for individuals with SCI.

\section{MATERIALS AND METHODS}

\section{Search strategy}

Electronic searches were conducted between January and February, 2016. The following databases were searched: AMED, EMBASE, HMIC, BNI, Medline, PsycInfo, CINAHL and HEALTH BUSINESS ELITE. The Cochrane database was also searched for existing relevant literature reviews, but none were found. The key words used to search the database were as follows: (spinal AND cord AND injury) OR (SCI) OR (spinal AND injur*)) AND (suicide) OR (selfharm) OR (suicidal). These search terms were identified in either the title or the abstract of journal articles in each database. A total of 404 results were found. Titles and abstracts were screened of each article to identify whether it was relevant; this identified 81 articles. Full texts of the identified articles were then viewed to identify studies relevant to the current literature review. Reference lists

${ }^{1}$ Department of Clinical Psychology, The National Spinal Injuries Centre, Stoke Mandeville Hospital, Buckinghamshire, UK and ${ }^{2}$ Oxford Institute of Clinical Psychology Training, University of Oxford, Oxford, UK

Correspondence: L Garmon-Jones, National Spinal Injuries Centre, Clinical Psychology, Stoke Mandeville Hospital, Mandeville Road, Aylesbury HP21 8AL, UK.

E-mail: lydia.garmon-jones@buckshealthcare.nhs.uk

Received 13 May 2016; revised 25 July 2016; accepted 10 August 2016; published online 27 September 2016 


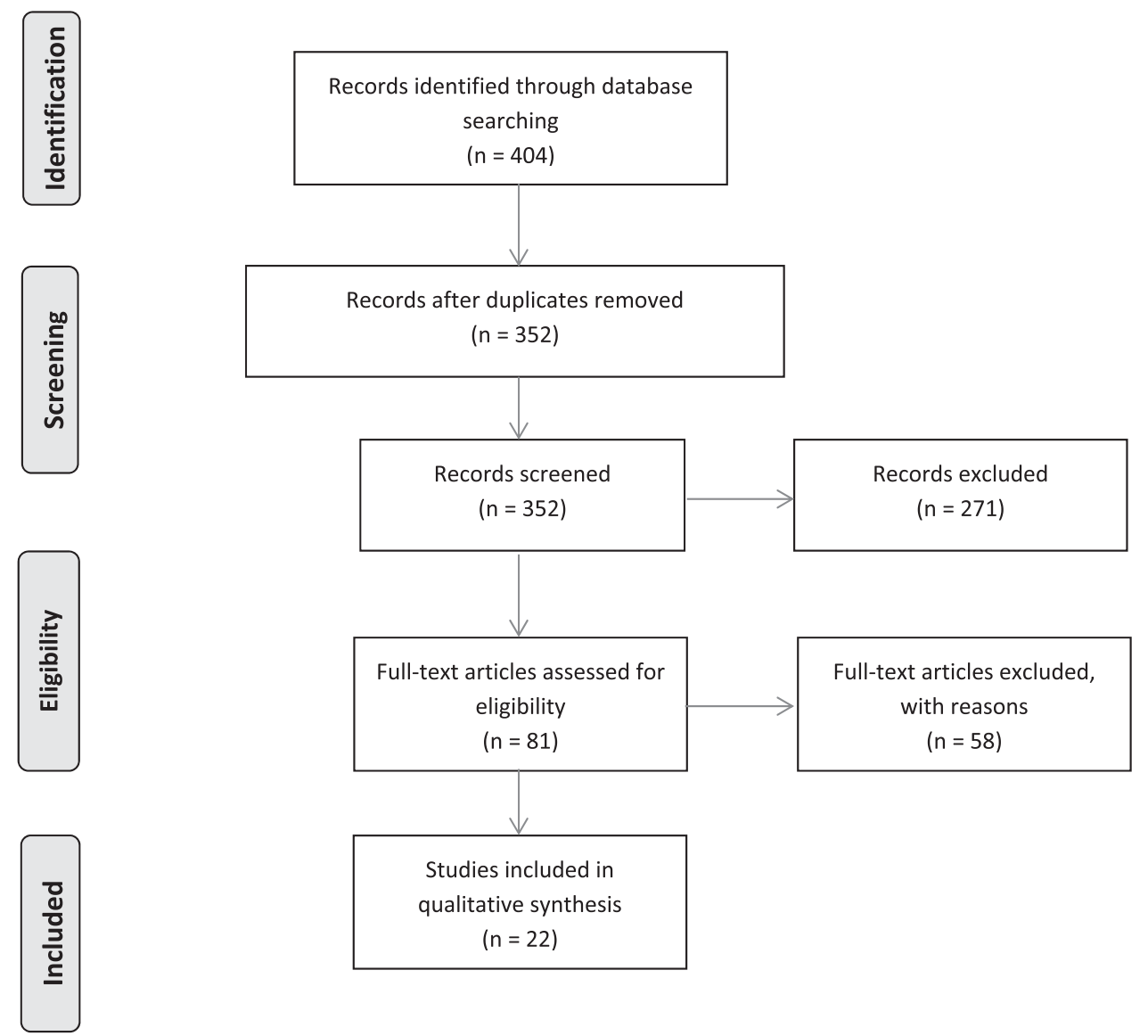

Figure 1 Flow diagram illustrating the selection process for the relevant studies included in this literature review. ${ }^{6}$ A full color version of this figure is available at the Spinal Cord journal online.

of relevant articles were scanned to identify additional relevant papers. Papers published between 1990 and 2016 in English were included in this review. If full texts were unavailable or only conference abstracts could be accessed, these studies were disregarded. This search resulted in a total of 22 relevant articles being identified to include in this literature review (Figure 1).

\section{RESULTS}

Twenty-two articles published between 1990 and 2016 were included in this literature review. The articles explored suicide in relation to SCI, investigating SCI caused by suicidal behaviour, the occurrence of suicide post SCI and the risk factors that are presented with suicidal behaviour in individuals with SCI. Results section will be shaped under the following headings:

1. Suicidal behaviour as a cause of SCI.

2. The occurrence of suicidal behaviour post SCI.

3. Risk factors associated with an increased possibility of suicidal behaviour post SCI.

\section{Suicide as a cause of SCI}

Ten studies looked at suicidal behaviour as a cause of SCI, of which nine studies reported the percentage of the given sample population who acquired their injury as a result of suicidal behaviour. As shown in Table 1, between 0 and $6.8 \%$ of the individuals with SCI included in these studies had acquired their injuries as a result of a suicide attempt. Additional unpublished data retrieved from the National Spinal Injuries Centre, Stoke Mandeville Hospital and North West
Regional Spinal Injuries Centre, Southport and Ormskirk hospital indicated that $2.6 \%$ of all new traumatic SCI admissions were as a result of attempted suicide (Savic G, personal correspondence, 27th April 2016). This is similar to the rate of $2.4 \%$ reported by the Queen Elizabeth National Spinal Injuries Unit in Scotland (Purcell M, personal correspondence, 29th April 2016).

Method of suicide attempt. Falling was commonly reported as the most frequently used method of suicidal behaviour; $85-98 \%$ of suicide attempts reported in the included studies were by 'falling' from windows or buildings. Stanford et al. ${ }^{8}$ reported that $98 \%$ of suicide attempts reported in their study were as a result of falling, and $2 \%$ as a result of gunshot injury. Kennedy et al. ${ }^{7}$ reported that $85 \%$ of suicide attempts in their sample were by falling. Papadakis et al. ${ }^{16}$ specified that $91 \%$ of suicide attempts were by falling from a building, $3 \%$ by falling from a window, $3 \%$ by falling from a bridge and $3 \%$ by falling inside the house. Anderson and Allan ${ }^{15}$ reported that $95 \%$ of suicide attempts were by falling, of which $63 \%$ occurred in a residential setting and $23 \%$ on bridges. Biering-Sorensen et al. ${ }^{9}$ reported that $84 \%$ of suicide attempts were caused by jumping from buildings. It should be noted that, although most studies report 'falling' as the method of suicide attempt, it is interpreted as being of an intentional nature.

\section{Suicide post SCI}

Ten studies examining suicide post SCI were identified. Six studies explored suicide as a cause of death and reported the proportion of deaths by suicide in their SCI sample. Two of the studies explored the 
Table 1 The percentage of $\mathrm{SCl}$ acquired by suicide attempts in each study

\begin{tabular}{|c|c|c|c|c|c|}
\hline Study & Country & SCl sample size & $\begin{array}{l}\text { Proportion of sample who acquired } \\
\text { SCl from suicide attempt (\%) }\end{array}$ & Age & Sex \\
\hline Kennedy et al. ${ }^{7}$ & UK & 137 & 1.6 & $14-65$ & $\begin{array}{l}68 \text { male } \\
69 \text { female }\end{array}$ \\
\hline Stanford et al. ${ }^{8}$ & Australia & 2752 & 2.03 & $15-74$ & $\begin{array}{l}20 \text { female } \\
36 \text { male (of cases identified) }\end{array}$ \\
\hline Biering-Sørensen et al. ${ }^{9}$ & Denmark & 657 & 6.8 & $17-59$ & $\begin{array}{l}28 \text { female } \\
17 \text { male (of cases identified) }\end{array}$ \\
\hline Wu et al. ${ }^{11}$ & Taiwan & 41586 & 2.3 & $20+$ & $\begin{array}{l}15729 \text { female } \\
25857 \text { male }\end{array}$ \\
\hline Pagliacci et al. ${ }^{12}$ & Italy & 684 & 4.3 & $11-94$ & $\begin{array}{l}80 \% \text { male } \\
20 \% \text { female }\end{array}$ \\
\hline Anderson and Allan ${ }^{15}$ & UK & 2343 & 1.96 & NA & $\begin{array}{l}21 \text { male } \\
25 \text { female (of cases identified) }\end{array}$ \\
\hline
\end{tabular}

Abbreviations: NA, not applicable; SCl, spinal cord injury.

Table 2 The proportion of deaths as a result of suicide in $\mathrm{SCl}$ studies

\begin{tabular}{|c|c|c|c|c|c|c|}
\hline Study & Country & SCl sample size & No. of deaths & Deaths by suicide (\%) & Age & Sex \\
\hline Ahoniemi et al. ${ }^{17}$ & Finland & 1647 & 419 & 10 & $\begin{array}{l}\text { Mean age at death: } 55.5 \text { (male) } \\
58.2 \text { (female) }\end{array}$ & $\begin{array}{l}360 \text { male } \\
59 \text { female (of cases identified) }\end{array}$ \\
\hline Hagen et al. ${ }^{18}$ & Norway & 401 & 173 & 5.8 & Mean: 42.7 & $\begin{array}{l}331 \text { male } \\
70 \text { female }\end{array}$ \\
\hline Thietje et al. ${ }^{19}$ & Germany & 3114 & 268 (100 included) & 11 & NA & $\begin{array}{l}90 \text { male } \\
10 \text { female (of cases identified) }\end{array}$ \\
\hline Hartkopp et al. ${ }^{20}$ & Denmark & 888 & 236 & 9.7 & NA & $\begin{array}{l}713 \text { male } \\
175 \text { female }\end{array}$ \\
\hline Charlifue and Gerhart ${ }^{21}$ & USA & 5200 & 489 & 9 & $15-68$ & $\begin{array}{l}37 \text { male } \\
5 \text { female (of cases identified) }\end{array}$ \\
\hline DeVivo et al..22 & USA & 9135 & 854 & 5.9 & NA & $\begin{array}{l}46 \text { male } \\
4 \text { female (of cases identified) }\end{array}$ \\
\hline Cao et al. ${ }^{3}$ & USA & 31339 & 5167 & 3.83 & NA & NA \\
\hline Sabre et al. ${ }^{23}$ & Estonia & 595 & 162 & 8 & $\begin{array}{l}51.0 \pm 17.5 \text { (male) } \\
49.9 \pm 19.3 \text { (female) }\end{array}$ & $\begin{array}{l}139 \text { male } \\
24 \text { female (of cases identified) }\end{array}$ \\
\hline
\end{tabular}

Abbreviations: NA, not applicable; SCl, spinal cord injury.

presence of suicidal ideation and attempts at suicide post SCI. Three studies reported the method of suicide that was used.

Suicide as a cause of death post SCI. Six studies included in this review identified suicide as a cause of death following SCI. The number of deaths within SCI samples ranged between 100 and 489 individuals. These deaths were studied to identify the proportion that occurred as a result of suicide. Between 5.8 and $11 \%$ of deaths were as a result of suicide (Table 2).

Suicidal ideation post SCI. Nam et al. ${ }^{24}$ explored suicidal ideation in a sample of 368 individuals with SCI and in a matched control group of 1104 individuals without SCI. Suicidal ideation was found in 35\% of the SCI group and in $10 \%$ of the non-SCI control group. Among these, $17 \%$ of the SCI group had previously attempted suicide, whereas $9 \%$ of individuals in the non-SCI group had previously attempted suicide. Kishi et al. ${ }^{25}$ studied a sample of 60 people with SCI, and found that in an initial evaluation $13 \%$ had a suicide plan. At 3 months' follow-up, 47 people with SCI were interviewed; $11 \%$ had a suicide plan, of which 2 individuals had been suicidal at the initial evaluation. At 6 months' follow up, 32 people with SCI were interviewed, of which $13 \%$ reported suicide plans, all of whom had been suicidal during the initial evaluation, indicating no new cases.

Method of suicide used post SCI. DeVivo et al. ${ }^{22}$ reported gunshot as the most common method of suicide $(50 \%)$, followed by overdose (16\%), cutting (10\%), suffocation $(6 \%)$, drowning $(6 \%)$, falls from heights $(4 \%)$ and $8 \%$ unspecified. Similarly, Charlifue and Gerhart ${ }^{21}$ also reported firearms as the leading cause of suicide in their sample (55\%), followed by overdose (21\%), hanging (7\%) and jumping off a building (5\%). In contrast, Hartkopp et al..$^{20}$ reported overdose as the most common method (48\%), followed by drowning (22\%), hanging 
(17\%), train (4\%), shooting (4\%) and fall (4\%). In a study of six SCI cases who committed suicide, one was from a suicide/homicide pact with a close friend, one from a gunshot, one as a result of electrocution, one from an overdose, one from an explosion and one unspecified. $^{26}$ The availability of access to firearms is a likely explanation for the difference between Europe and the USA.

Risk factors associated with suicidal behaviour post SCI

Psychiatric disorders. A large proportion of the literature indicated that psychiatric disorders are significant risk factors for suicidal behaviour both before and after SCI.

Psychiatric disorders before SCI. Psychiatric diagnoses in those who had acquired their SCI following a suicide attempt were reported in a number of studies. Kennedy et al. ${ }^{7}$ demonstrated that a diagnosis of schizophrenia was present in $33 \%$ and depression was reported in $27 \%$ of their sample of suicide attempts resulting in SCI. Stanford et al. ${ }^{8}$ reported that, of their sample, $48 \%$ had a personality disorder, $29 \%$ had schizophrenia, $25 \%$ had major depression, $18 \%$ had chronic alcohol abuse, $18 \%$ had a mood disorder, $5 \%$ had bipolar disorder, $2 \%$ had schizoaffective disorder and chronic substance abuse was reported in $18 \%$. Papadakis et al. ${ }^{16}$ reported that $38 \%$ of their sample had a diagnosis of schizophrenia, 25\% had depression, $9 \%$ had reported history of alcohol/drug abuse, 3\% had a personality disorder, $3 \%$ were bipolar and $3 \%$ had a psychiatric diagnosis not specified. Biering-Sørensen et al. ${ }^{9}$ reported that $62 \%$ of their sample had previously been hospitalised due to psychiatric issues. Finally, Anderson and Allan ${ }^{15}$ reported that $82 \%$ of their sample had preexisting mental health issues, and $24 \%$ had diagnoses established post SCI.

Suicide post SCI. In a study of six individuals who committed suicide post SCI, five of the six individuals had developed moderate to severe depression as inpatients. It was also found that schizoid and narcissistic personality traits were present, as well as a history of alcohol/drug abuse. ${ }^{26}$ Hartkopp et al. ${ }^{20}$ reported that $34.8 \%$ of their suicidal SCI sample had a psychiatric diagnosis, compared with only $7.6 \%$ in the natural death group. McCullumsmith et al. ${ }^{27}$ reported that, of those with a history of suicide attempts, $7 \%$ had received treatment for schizophrenia and $15 \%$ for bipolar disorder. It was also noted that $62 \%$ had taken medication for the treatment of depression. Looking at the characteristics of individuals with SCI who committed suicide, $14 \%$ of individuals had a psychiatric history before injury and $12 \%$ after injury. ${ }^{21}$

Previous suicide attempts. Suicide attempts before an attempt that resulted in SCI injury appeared to be common, with proportions of previous suicide attempt being highlighted in studies as follows: $23 \%$ (Stanford et al. ${ }^{8}$ ), 23\% (Kennedy et al. ${ }^{7}$ ), and 31\% (Biering-Sorensen et al. ${ }^{9}$ ). McCullumsith et al. ${ }^{27}$ found that $64 \%$ of their SCI sample had made a suicide attempt before their injury, $47 \%$ after and $6 \%$ both before and after.

Employment. Before SCI. Employment was reported as a potential risk factor in a number of studies. Of those who acquired their injury as a result of attempted suicide, Kennedy et al. ${ }^{7}$ reported that $42.3 \%$ were employed, Papadakis et al. ${ }^{16}$ reported an employment rate of $41 \%$ and Biering-Sorensen et al. ${ }^{9}$ reported unemployment in $62 \%$ of their sample; this included those receiving early pension.

Post SCI. Observing employment rates in individuals with a spinal cord injury, it was reported that $58 \%$ of participants were pensioned owing to physical disability. ${ }^{28}$ It was suggested that possible isolation as a consequence of being unemployed could impair social integration and psychological well-being.

Level of injury. Suicide was found to be more common among patients with paraplegic injuries in four studies. Hagen et al. ${ }^{18}$ reported that $70 \%$ of the sample who committed suicide had a thoracolumbosacral injury. In the study by DeVivo et al, ${ }^{22} 60 \%$ of suicides occurred among people with paraplegia. Ahoniemi et al. ${ }^{17}$ reported that $17 \%$ of males and $27 \%$ of females with paraplegia died as a result of suicide compared with $5.8 \%$ of males and $0 \%$ of females with tetraplegia. Cao et al. ${ }^{3}$ also reported suicide to occur more among people with paraplegia, reporting an odds ratio of 1.72 . However, conflicting with this suggestion, Thietje et al. ${ }^{19}$ found that $82 \%$ of the individuals who had committed suicide had tetraplegia. Exploring the influence of completeness of injury, McCullumsmith et al. ${ }^{27}$ reported higher suicide rates in complete paraplegia injuries of $36 \%$ when compared with $22 \%$ incomplete paraplegia injuries. However, Hartkopp et al. ${ }^{20}$ found no difference between functional group or level of lesion and suicide rate.

\section{Gender}

Two studies suggested that women are at a higher risk of committing suicide. ${ }^{18,24}$ In the study by Hagen et al., ${ }^{18}$ cause-specific standardised mortality rate for suicide was 3.7 in males and 37.6 in females. Nam et al. ${ }^{24}$ reported female gender to be a significant risk factor for suicidal ideation, with an odds ratio of 3.7. However, interestingly, in one study, all those who committed suicide were male. ${ }^{23}$ Nevertheless, owing to the small sample size, it is not possible to suggest this as a significant risk.

\section{DISCUSSION}

\section{Summary of findings}

The findings of this literature review suggest that suicidal behaviour accounts for a small percentage of those acquiring an SCI. The predominant method used in these attempts is deliberate falling/ jumping from windows, buildings and bridges. Suicidal behaviour post SCI is frequently reported as a cause of death; the predominant methods reported are gunshot and overdose contrasting with the methods used before SCI in the USA and in Europe. This difference in method may be a result of access issues with access to guns and physical access into high buildings. In any case, when conducting a risk assessment access to firearms, drugs/medication and heights need to be explored.

Psychiatric diagnosis is commonly reported as a prominent risk factor for suicidal behaviour both before and after SCI - in particular, schizophrenia, personality disorder and depression. These findings highlight the need for effective psychological and psychiatric assessment and intervention for those with mental health issues to reduce the risk of suicidal behaviour. It also suggests the importance of risk assessment both during and after rehabilitation, especially for those individuals who have previously attempted suicide. Previous suicide attempts place individuals at higher risk of re-attempting. ${ }^{5}$ The findings of the current review support this. ${ }^{7-9,27}$

Other risk factors highlighted in this review included employment status and level of injury. High levels of unemployment have been found in studies of individuals who have attempted suicide. ${ }^{7,9,16,28}$ As suggested, isolation caused by unemployment may impair social integration and psychological well-being and therefore increase the risk of suicidal behaviour. ${ }^{28}$ Level of injury as a risk factor is portrayed by conflicting findings. Although there are findings suggesting that 
individuals with paraplegia are at higher risk, ${ }^{3,17,18,22}$ there are also findings that suggest that individuals with tetraplegia are as well. ${ }^{19}$ In addition, one study reported no difference between differing levels of injury. ${ }^{24}$ It is therefore not possible to draw an accurate conclusion from these findings. However, one suggestion is that isolation may have a role in increasing the risk of suicidal behaviour. It is suggested that individuals with higher level, more complete injuries require more assistance, and therefore are not as isolated as those individuals with lower level, more incomplete injuries who need less support and therefore may become isolated. Therefore, social isolation is a possible risk factor, which requires attention.

\section{Critique of literature}

Implications for research. This literature review highlights the need for more data on the incidence rate of suicide attempts both before and after SCI. In addition, more detailed information on the causes of death post SCI and further psychological autopsies, similar to Kewman and Tate's, ${ }^{29}$ could increase our understanding regarding suicide risk in SCI. This review highlights that information regarding the level and grade of injury is not clearly presented across research in this specific area. In identifying these data, it could be possible to further explore the nature of injury as a risk factor, and tailor specific interventions for individuals with different injuries to increase effectiveness.

Implications for clinical practice. The clinical implications of this review highlight a need for risk assessment throughout rehabilitation and continuing post discharge. Services should have risk assessment policies for suicide and self-harm for mental health staff. Guidelines for assessment of risk, note taking and monitoring should also be available for all clinical staff. Findings suggest that individuals with SCI are at highest risk in the years immediately following injury; therefore, it is particularly important to monitor and ensure support is available in the first years after discharge. Mental health in general should also be monitored. Psychiatric disorders have been reported as one of the main risk factors for suicide attempt. Combining our research findings with insight from clinical experience, the main risk factors identified for suicide in spinal cord injury include history of mental illness, substance abuse, traumatic experiences, previous suicide attempts, excessive threat perceptions, limited social support, family fragmentation, easy access to means, sleep disturbance and poor access to psychological support in the community. However, it is not only important to consider the management of risk factors but also the promotion of protective factors, to decrease the risk of suicidal behaviour in individuals with SCI. The important protective factors that have been concluded from both research and clinical experience include sense of control; acceptance and hope; personal resilience; quality social support; relational commitments; purpose in life; ability to perceive injury as a challenge, rather than a threat; engagement and social participation and access to responsive support systems. It is important that risk factors are considered and managed, and protective factors receive sufficient attention and encouragement when working with individuals with SCI.

Critique of the literature review. This literature review highlights the issue of suicide in SCI, providing useful information regarding risk factors for suicidal behaviour both before and after injury. However, one issue that has arisen from this review is that it does not appear possible to gain an accurate general prevalence rate for suicide following SCI, as indicated by differing reported rates. Owing to the nature of suicide, it is not always specified as the cause of death. ${ }^{30}$ In some cases it is not possible to confirm that a death was solely as a result of a suicide attempt, or identify the individual's intentions when such an event occurred. In addition, it is possible that the suicide rate is higher than reported, as often this may be reported as an accident, for example. In addition, relevant and useful data such as age, gender, level of injury and socioeconomic factors are not clearly specified across all studies. This makes it challenging to draw conclusions with regard to individuals who may be at a higher risk than others depending on their level of injury, for example. More specific, detailed data on individuals included in such studies would allow for more in-depth analysis of such factors.

\section{CONCLUSION}

In conclusion, we have reviewed the literature exploring suicide before and after SCI, indicating incidence rates and risk factors for suicide attempts. Although it is not possible to be very precise, we conclude that the suicide accounts for between 4 and $11 \%$ of deaths following SCI. The main risk factor associated with suicide in SCI is the presence of psychiatric disorders, highlighting a crucial need for risk assessment and psychological intervention for mental health issues following injury. Further research is needed to provide more specific data on other risk factors that may contribute to suicide in SCI.

\section{DATA ARCHIVING}

There were no data to deposit.

\section{CONFLICT OF INTEREST}

The authors declare no conflict of interest.

\section{ACKNOWLEDGEMENTS}

We thank Dr Gordana Savic, Clinical Scientist, National Spinal Injuries Centre, Stoke Mandeville Hospital and Dr Mariel Purcell, Consultant in Spinal Injuries, Queen Elizabeth National Spinal Injuries Unit, for providing us with data regarding suicide as a cause of SCI.

1 Mann JJ. Neurobiology of suicidal behaviour. Nat Rev Neurosci 2003; 4: 819-828.

2 Apter A. Suicide and suicidal behavior. Public Health Rev 2012; 34: 1.

3 Cao Y, Massaro JF, Krause JS, Chen Y, Devivo MJ. Suicide mortality after spinal cord injury in the United States: injury cohorts analysis. Arch Phys Med Rehabil 2014; 95 : 230-235.

4 Berman AL, Silverman MM, Bongar BM. Comprehensive Textbook of Suicidology. Guilford Press: New York, NY, USA, 2000.

5 Tidemalm D, Långström N, Lichtenstein $P$, Runeson $B$. Risk of suicide after suicide attempt according to coexisting psychiatric disorder: Swedish cohort study with long term follow-up. Brit Med J 2008; 337: a2205.

6 Moher D, Liberati A, Tetzlaff J, Altman DG, PRISMA Group. Preferred reporting items for systematic reviews and meta analyses: the PRISMA statement. Brit Med J 2009; 339: b2535.

7 Kennedy P, Rogers B, Speer S, Frankel H. Spinal cord injuries and attempted suicide: a retrospective review. Spinal Cord 1999; 37: 847-852.

8 Stanford RE, Soden R, Bartrop R, Mikk M, Taylor TK. Spinal cord and related injuries after attempted suicide: psychiatric diagnosis and long-term follow-up. Spinal Cord 2007; 45: 437-443.

9 Biering-Sørensen F, Pedersen W, Müller PG. Spinal cord injury due to suicide attempts. Spinal Cord 1992; 30: 139-144.

10 McCammon JR, Ethans K. Spinal cord injury in Manitoba: a provincial epidemiological study. J Spinal Cord Med 2011; 34: 6-10.

11 Wu JC, Chen YC, Liu L, Chen TJ, Huang WC, Cheng $\mathrm{H}$ et al. Effects of age, gender, and socio-economic status on the incidence of spinal cord injury: an assessment using the eleven-year comprehensive nationwide database of Taiwan. J Neurotrauma 2012; 29: 889-897.

12 Pagliacci MC, Celani MG, Zampolini M, Spizzichino L, Franceschini M, Baratta S et al. An Italian survey of traumatic spinal cord injury. The Gruppo Italiano studio epidemiologico Mielolesioni study. Arch Phys Med Rehabil 2003; 84: 1266-1275.

13 Pickett W, Simpson K, Walker J, Brison RJ. Traumatic spinal cord injury in Ontario, Canada. J Trauma Acute Care Surg 2003; 55: 1070-1076.

14 Exner G, Meinecke FW. Trends in the treatment of patients with spinal cord lesions seen within a period of 20 years in German centers. Spinal Cord 1997; 35: 7. 
15 Anderson J, Allan DB. Vertebral fracture secondary to suicide attempt: demographics and patient outcome in a Scottish spinal rehabilitation unit. J Spinal Cord Med 2011; 34: 380-387.

16 Papadakis SA, Galanakos S, Apostolaki K, Kateros K, Antoniadou O, Macheras G et al Spinal cord injuries following suicide attempts. In: Dionyssiotis $Y$ (ed.). Topics in Paraplegia, Chapter 3. InTech: Athens, Greece, 2014, pp 53-70.

17 Ahoniemi E, Pohjolainen T, Kautiainen H. Survival after spinal cord injury in Finland. J Rehabil Med 2011; 43: 481-485.

18 Hagen EM, Lie SA, Rekand T, Gilhus NE, Gronning M. Mortality after traumatic spinal cord injury: 50 years of follow-up. J Neurol Neurosurg Psychiatry 2010; 81: 368-373.

19 Thietje R, Pouw MH, Schulz AP, Kienast B, Hirschfeld S. Mortality in patients with traumatic spinal cord injury: descriptive analysis of 62 deceased subjects. J Spinal Cord Med 2011; 34: 482-487.

20 Hartkopp A, Brønnum-Hansen H, Seidenschnur AM, Biering-Sorensen F. Suicide in a spinal cord injured population: its relation to functional status. Arch Phys Med Rehabil 1998; 79: 1356-1361.

21 Charlifue SW, Gerhart KA. Behavioral and demographic predictors of suicide after traumatic spinal cord injury. Arch Phys Med Rehabil 1991; 72: 488-492.
22 DeVivo MJ, Black KJ, Richards JS, Stover SL. Suicide following spinal cord injury. Paraplegia 1991; 29: 620-627.

23 Sabre L, Rekand T, Asser T, Kõrv J. Mortality and causes of death after traumatic spinal cord injury in Estonia. J Spinal Cord Med 2013; 36: 687-694.

24 Nam HS, Kim HR, Ha TH, Shin HI. Suicidal ideation in Korean persons with spina cord injury. Spinal Cord 2013; 51: 789-793.

25 Kishi Y, Robinson RG. Suicidal plans following spinal cord injury: a six-month study. J Neuropsychiatry Clin Neurosci 1996; 8: 442-445.

26 Judd FK, Brown DJ. Suicide following acute traumatic spinal cord injury. Spinal Cord 1992: 30: 173-177.

27 McCullumsmith CB, Kalpakjian CZ, Richards JS, Forchheimer M, Heinemann AW, Richardson EJ et al. Novel risk factors associated with current suicidal ideation and lifetime suicide attempts in individuals with spinal cord injury. Arch Phys Med Rehabil 2015; 96: 799-808.

28 Jurišić $\mathrm{B}$, Marušič† A. Suicidal ideation and behavior and some psychological correlates in physically disabled motor-vehicle accident survivors. Crisis 2009; 30: 34-38.

29 Kewman DG, Tate DG. Suicide in SCl: a psychological autopsy. Rehabil Psychol 1998; 43: 143.

30 Harris EC, Barraclough B. Suicide as an outcome for mental disorders. A meta-analysis. Br J Psychiatry 1997; 170: 205-228. 